\title{
FACTORS ASSOCIATED WITH CAREGIVER BURDEN AMONG CAREGIVERS OF CEREBRAL PALSY CHILDREN.
}

1. DPT, MS-OMPT

Clinical Demonstrator RCR\&AHS, Riphah International University, Lahore.

2. DPT, MS-OMPT

Clinical Demonstrator RCR\&AHS, Riphah International University, Lahore.

3. MBBS

Post Graduate Trainee Ghurki Trust Teaching Hospital.

4. Ph.D Scholar, MS-OMPT, MS-PT, BS-PT

Associate Professor RCR\&AHS, Riphah International University, Pakistan.

5. Ph.D Scholar, M-Phil Physiology, MS-PT, BS-PT

Assistant Professor RCR\&AHS, Riphah International University, Pakistan.

6. Ph.D Scholar, M.Phil, MBBS Associate Professor Biochemistry Independent Medical College, Faisalabad.

Correspondence Address:

Dr. Aiza Yousaf

RCR\&AHS, Riphah International

University, Lahore.

dc.aizayousaf@gmail.com

Article received on:

28/03/2020

Accepted for publication:

25/05/2020

\section{INTRODUCTION}

A cerebral palsy is a group of neurological disorders that cause permanent and nonprogressive damage of motor areas of immature brain occurring during childbirth or after it and produce movement dysfunction, posture, balance and muscular in coordination and may lead to a limitation of activities or other musculoskeletal problems. ${ }^{1-4}$ Worldwide prevalence of cerebral palsy is 2 to 2.5 cases per 1,000 births. ${ }^{4,5}$

Caregiving for these CP children causes burden of care because these children are different from normal ones and need extra care and attention in regards to their physical disabilities and limitations. This type of burden may adversely impact on caregiver's physical and mental functioning, child behavior and health and family relations. ${ }^{6}$

Caregiver burden is a combination of both a precursor and consequence of many influences in everyday life associated with caregiving experience, such as the role of family support, interpersonal relationships, child illness, disability, mental disorder or differences among siblings raised in same home. If this burden persists, it may lead to parent's health deconditioning as well as serious physical and behavioral disorders of the child. ${ }^{7,8}$

Most of the recent studies concluded that parent caregivers of $\mathrm{CP}$ children, in general with parent caregivers of children with other chronic 
developmental disabilities, are at an amplified hazard for caregiver burden ${ }^{9}$, anxious/depressive symptoms ${ }^{10,11}$, decreased psychological wellbeing and decreased health. . $^{3,6,12}$

Despite the fact that modern-day studies on the caregiver's burden of disabled children continue to be rare, a few investigations have demonstrated the onset of burden and stress in caregivers of disabled children due to presence of many distinct which in large part correspond with those found in the previously mentioned researches. ${ }^{10,11,13}$

The prevalence of cerebral palsy is high in Pakistan, however, it needs to be further explored. Because after intensive literature search, it was developed that the parenting or caregiving burden details regarding frequency, types and etiology of $\mathrm{CP}$ is very scarce in our country. So, the aim of the study was to measure the association of factors with the presence of burden on primary caregivers of children with cerebral palsy $(\mathrm{CP})$.

\section{MATERIAL \& METHODS}

This study was a cross-sectional observational study which was completed in 4 months duration from February 2017 to June 2017 after the approval of synopsis and data was collected from Outpatient Department of Physical Therapy, Children Hospital Lahore, Outpatient Department of Physical Therapy, Pakistan Society for the Rehabilitation of the Disabled (PSRD), Lahore and Mobility Quest, Cavalry Ground-Cantt, Lahore.

A total of sample 100 was taken through nonprobability convenient sampling technique. Caregivers of CP children (aged less than 18 years) who were the main caregiver of their $\mathrm{CP}$ child were included. Primary caregivers who had any disease or problem, had additional care giving responsibilities outside of routine parental care such as caring for a disabled adult or an elderly person, employed caregiver or hired a maid or nurse for taking care of a baby were excluded. Informed consent was taken from the caregivers of CP children. Then, each participant filled a questionnaire which includes questions on socio-demographic details of the caregiver and child, and child's past medical history and the presence of functional impairments. Medical records were used to confirm type of cerebral palsy and functional impairments the of the child and Gross Motor Function Classification System (GMFCS) level respectively. ${ }^{14,15}$

To evaluate caregiver burden, the Caregiver Difficulties Scale (CDS), was used which is the 25 item questionnaire. ${ }^{16}$ All item were scored on a 5-point (0-4) Likert-type scale, they were indicating the amount of each caregiving experience as perceived by the respondent; with a final total score ranging from 0 to 100 . CDS total score less than 50 represents presence of increased caregiver burden while CDS score more than 50 represents minimum caregiver burden. The data was analyzed using SPSS version 25. Statistical significance was $P=0.05$. Descriptive Statistics like Frequency tables were used to show summary of CDS score and other variables, and Pearson correlation was used to see association among CDS score and other variables.

\section{RESULTS}

Demographic characteristics of the caregivers who participated in the study are shown in Table-I. The mean age of caregivers was 34.15 years (SD $=6.77$ ), $100 \%$ of whom were mothers of children with cerebral palsy. The mean age of the children was 6.35 years $(S D=4.52), 57 \%$ were boys and $43 \%$ were girls.

\begin{tabular}{|c|c|c|}
\hline Variables & \multicolumn{2}{|l|}{ Mean / Frequency } \\
\hline Gender (M / F ) & $57 / 43$ & \\
\hline Child age & $6.35 \pm 4.52$ & \\
\hline Caregiver age & $34.15 \pm 6.77$ & \\
\hline \multirow{3}{*}{$\begin{array}{l}\text { Caregiver } \\
\text { Education }\end{array}$} & Post primary or less & 32 \\
\hline & Secondary & 22 \\
\hline & Tertiary & 46 \\
\hline \multirow{3}{*}{$\begin{array}{l}\text { Socioeconomic } \\
\text { Status }\end{array}$} & Upper class & 17 \\
\hline & Middle class & 60 \\
\hline & Lower class & 23 \\
\hline \multirow{3}{*}{$\begin{array}{l}\text { Number of } \\
\text { Children }\end{array}$} & Only child & 20 \\
\hline & 1 sibling & 32 \\
\hline & 2 or more siblings & 48 \\
\hline \multirow{2}{*}{$\begin{array}{l}\text { Family } \\
\text { Structure }\end{array}$} & Nuclear & 67 \\
\hline & Three generations or extended & 33 \\
\hline \multirow{2}{*}{$\begin{array}{l}\text { Geographical } \\
\text { area }\end{array}$} & Urban & 84 \\
\hline & Rural & 16 \\
\hline $\begin{array}{l}\text { Age of child at time } \\
\text { of diagnosis in } \\
\text { months }\end{array}$ & $12.99 \pm 7.50$ & \\
\hline \multicolumn{3}{|c|}{ Table-I. Caregiver characteristics $(\mathrm{N}=100)$} \\
\hline
\end{tabular}


Different demographic variables were assessed for association with CDS scores. Geographical area, socioeconomic status, caregiver's age, total number of children and CP child's age and gender have significant association with caregiver burden (Table-II).

\begin{tabular}{|l|c|c|}
\hline $\begin{array}{c}\text { Correlation of variables with } \\
\text { CDS Score }\end{array}$ & r. & P-Value \\
\hline Gender & 0.484 & $0.035^{\star}$ \\
\hline Child age & 0.249 & $0.013^{\star}$ \\
\hline Caregiver age & 0.239 & $0.017^{\star}$ \\
\hline Caregiver Education & 0.157 & 0.120 \\
\hline Socioeconomic Status & -0.243 & $0.015^{\star}$ \\
\hline Number of Children & 0.358 & $0.036^{\star}$ \\
\hline Family Structure & -0.176 & 0.079 \\
\hline Geographical area & -0.240 & $0.016^{\star}$ \\
\hline $\begin{array}{l}\text { Age of child at time of diagnosis } \\
\text { in months }\end{array}$ & -0.103 & 0.308 \\
\hline Type of cerebral palsy & 0.118 & 0.244 \\
\hline GMFCS. 2 to <4 & 0.061 & 0.546 \\
\hline GMFCS. 4 to <6 & 0.037 & 0.718 \\
\hline GMFCS. 6 to <12 & 0.031 & 0.762 \\
\hline GMFCS. 12 to 18 & -0.209 & $0.037^{\star}$ \\
\hline Table-II. Correlation of independent variables with \\
$\begin{array}{l}\text { caregiver burden (CDS Score) } \\
\text { *Correlation significant at } 0.05\end{array}$ \\
\hline
\end{tabular}

\section{DISCUSSION}

Caregiver burden is an imperative worry among caregivers of cerebral palsy affected children. Limiting caregiver burden can prompt enhanced psychological wellness results for both parental figure and children. ${ }^{16}$ In Pakistan as a collectivistic culture, stress among caregivers is likely to differ from Europe (which have individualistic culture). ${ }^{16,17}$ Subsequently, this study intended to investigate factors that are related to caregiver burden in Asian setting, which were also mentioned in earlier studies.

There is absence of rehabilitation services in rural areas due to which caregivers have to travel long way from those areas in public transport to get the routine treatment sessions of their $\mathrm{CP}$ child. This creates an extra burden for these caregiver as they spend much time to reach the urban areas. ${ }^{16}$ Family structure has no significant correlation with caregiver burden but socioeconomic status is significantly associated with caregiver burden. Interestingly, geographical territory and financial status both of these factors are freely connected with caregiver burden, because poverty expands the load for both the individuals who live in urban and rural territories. This result is supported as well as contradicted by previous researches, such as in a study concluded that the impacts of burden on the strength and prosperity of caregiver, the financial status is by all accounts an exceptionally significant. ${ }^{18}$ In a study, Raina et al. (2005) concluded that such factors have adverse effects on the physical condition and enthusiastic prosperity of the caregivers of CP children. These factors cannot be changed effortlessly, but they positively affect caregiver burden and indicate the need for mediations for them. ${ }^{12,13}$

The characteristics of CP child involve child age, gender, time of diagnosis of CP, level of disability and type of cerebral palsy. CP child age is significantly correlated with CDS score and shows significant association with increase caregiver burden because with progression of age of child, the demands of caring and dependency increase and result in increased caregiver burden. CP child gender is significantly correlated with CDS score and may be a source of significant caregiver burden while time of diagnosis of $\mathrm{CP}$ has no association with caregiver burden. Numerous researchers propose that one of the prime factors of the demands of care are children with disabilities due to chronic illnesses. ${ }^{12,13,19}$ But, according to result of this study, types of cerebral palsy and level of disability shows no correlation with caregiver burden. This result occur due to small sample size with variability of types of cerebral palsy and significant value ( $p$-value) is $>0.05$ as well because this study includes almost all different types of cerebral palsy and GMFCS level for different age group. As each type require individually appropriate number of sample size but due to lack of resources and time we get only small sample size of 100 caregivers as a whole. And GMFCS for different ages shows p-value > 0.05 . The current study had not considered the behavior problems of CP children, which can have an innumerable influence on caregiver burden 
along with the degree of debility. Furthermore, the CP child functional deficit assessment was confined to reports from their caregivers and details obtained from the medical histories.

\section{CONCLUSION}

The parameters studied for evaluating association with caregiver's burden, our study finds that geographical area, socioeconomic status, caregiver's age, total number of children and CP child's age and gender have significant association with caregiver burden while types of cerebral palsy and degree of disability has no correlation with caregiver burden. Further studies should be done by considering the quality of life, depression and self-efficacy of caregivers and to evaluate relationship between $\mathrm{CP}$ child improvement and caregiver burden.

Copyright@ 25 May, 2020.

\section{REFERANCES}

1. Rethlefsen SA, Ryan DD, Kay RM. Classification systems in cerebral palsy. Orthopedic Clinics of North America. 2010; 41(4):457-67.

2. Snider L, Majnemer A, Darsaklis V. Virtual reality as a therapeutic modality for children with cerebral palsy. Developmental Neurorehabilitation. 2010; 13(2):120-8.

3. Whittingham K, Wee D, Sanders M, Boyd R. Predictors of psychological adjustment, experienced parenting burden and chronic sorrow symptoms in parents of children with cerebral palsy. Child: Care, Health and Development. 2013; 39(3):366-73.

4. Manzoor N, Kashif M, Haroon B, Dastgir A, Iram $\mathrm{H}$. Parent's perception of constraint induced movement therapy in cerebral palsy management in rehabilitation centers of Lahore. JPMA 2019; 69(3):373-7.

5. Blair E. Epidemiology of the cerebral palsies. Orthopedic Clinics of North America. 2010; 41(4):44155.

6. Brehaut JC, Kohen DE, Garner RE, Miller AR, Lach LM, Klassen AF, et al. Health among caregivers of children with health problems: Findings from a Canadian population-based study. American Journal of Public Health. 2009; 99(7):1254-62.

7. Kasuya RT, Polgar-Bailey MP, MPH Robbyn Takeuchi M. Caregiver burden and burnout a guide for primary care physicians. Postgraduate Medicine. 2000; 108(7):119.
8. Ketelaar M, Volman M, Gorter J, Vermeer A. Stress in parents of children with cerebral palsy: What sources of stress are we talking about? Child: Care, Health and Development. 2008; 34(6):825-9.

9. Cheshire A, Barlow JH, Powell LA. The psychosocial well-being of parents of children with cerebral palsy: a comparison study. Disability and rehabilitation. 2010; 32(20):1673-7.

10. Barlow J, Cullen\Powell L, Cheshire A. Psychological well $\square$ being among mothers of children with cerebral palsy. Early Child Development and Care. 2006; 176(34):421-8.

11. Wang H-Y, Jong Y-J. Parental stress and related factors in parents of children with cerebral palsy. The Kaohsiung Journal of Medical Sciences. 2004; 20(7):334-40.

12. Raina P, O'Donnell M, Rosenbaum P, Brehaut J, Walter $S D$, Russell $D$, et al. The health and well-being of caregivers of children with cerebral palsy. Pediatrics. 2005; 115(6):e626-e36.

13. Marrón EM, Redolar-Ripol D, Boixadós M, Nieto R, Guillamón N, Hernández E, et al. Burden on caregivers of children with cerebral palsy: Predictors and related factors. Universitas Psychologica. 2013; 12(3):767-77.

14. Gross motor function classification system Expanded and Revised (GMFCS-ER): Physiopedia; 26 August 2018 [cited 2018]. Available from: https:// www.physio-pedia.com/index.php?title=Gross Motor Function_Classification_System_-_Expanded_and_Revised_(GMFCS-ER)\&oldid=196565.

15. Sellers D, Mandy A, Pennington L, Hankins M, Morris C. Development and reliability of a system to classify the eating and drinking ability of people with cerebral palsy. Developmental Medicine \& Child Neurology. 2014; 56(3):245-51.

16. Wijesinghe CJ, Cunningham N, Fonseka P, Hewage CG, Østbye T. Factors associated with caregiver burden among caregivers of children with cerebral palsy in Sri Lanka. Asia Pacific Journal of Public Health. 2015; 27(1):85-95.

17. Giunta N, Chow J, Scharlach AE, Dal Santo TS. Racial and ethnic differences in family caregiving in California. Journal of Human Behavior in the Social Environment. 2004; 9(4):85-109.

18. McEwen BS, Gianaros PJ. Central role of the brain in stress and adaptation: Links to socioeconomic status, health, and disease. Annals of the New York Academy of Sciences. 2010; 1186(1):190-222.

19. Raina P, O'Donnell M, Schwellnus H, Rosenbaum P, King 
G, Brehaut $J$, et al. Caregiving process and caregiver burden: Conceptual models to guide research and practice. BMC pediatrics. 2004; 4(1):1.

\begin{tabular}{|c|c|c|c|}
\hline \multicolumn{4}{|c|}{ AUTHORSHIP AND CONTRIBUTION DECLARATION } \\
\hline Sr. \# & Author(s) Full Name & Contribution to the paper & Author(s) Signature \\
\hline 1 & Aiza Yousaf & $\begin{array}{l}\text { Concept, Hypothesis generation, } \\
\text { Critical review, Final proof reading. }\end{array}$ & Alza \\
\hline 2 & Hira lqbal & $\begin{array}{l}\text { Data collection, Literature search, } \\
\text { Literature review. }\end{array}$ & Hlppal \\
\hline 3 & Rabeea Zubair & Data collection, Data analysis. & Rebecte \\
\hline 4 & Muhammad Kashif & $\begin{array}{l}\text { Data interpretation, compiling of the } \\
\text { resutls. }\end{array}$ & 政 \\
\hline 5 & Danish Hassan & Data collection, writing of the article. & Dassiscriftasem \\
\hline 6 & Rizwan Ahmed & $\begin{array}{l}\text { Designed research methdology, } \\
\text { Writing of the article. }\end{array}$ & 20 minged. \\
\hline
\end{tabular}

